\title{
Gas Nozzle Effect on the Deposition of Polysilicon by Monosilane Siemens Reactor
}

\author{
Seung Oh Kang, Uk June Lee, Seung Hyun Kim, Ho Jung You, Kun Park, Sung Eun Park, \\ and Jong Hoon Park
}

Technical ReD Center, Semi-Materials Co., Ltd., Youngcheon, Gyeongbuk 770-803, Republic of Korea

Correspondence should be addressed to Jong Hoon Park, jhpark@semimaterials.com

Received 31 August 2011; Accepted 15 December 2011

Academic Editor: Bhushan Sopori

Copyright $\odot 2012$ Seung Oh Kang et al. This is an open access article distributed under the Creative Commons Attribution License, which permits unrestricted use, distribution, and reproduction in any medium, provided the original work is properly cited.

\begin{abstract}
Deposition of polysilicon (poly-Si) was tried to increase productivity of poly-Si by using two different types of gas nozzle in a monosilane Bell-jar Siemens (MS-Siemens) reactor. In a mass production of poly-Si, deposition rate and energy consumption are very important factors because they are main performance indicators of Siemens reactor and they are directly related with the production cost of poly-Si. Type A and B nozzles were used for investigating gas nozzle effect on the deposition of poly-Si in a MSSiemens reactor. Nozzle design was analyzed by computation cluid dynamics (CFD). Deposition rate and energy consumption of poly-Si were increased when the type B nozzle was used. The highest deposition rate was $1 \mathrm{~mm} / \mathrm{h}$, and the lowest energy consumption was $72 \mathrm{kWh} \cdot \mathrm{kg}^{-1}$ in this study.
\end{abstract}

\section{Introduction}

Poly-Si is widely used as a raw material in the semiconductor and photovoltaic industry. Generally, most of poly-Si produced by Siemens reactor are chemical vapor deposition (CVD) systems with mixed gas of monosilane $\left(\mathrm{SiH}_{4}, \mathrm{MS}\right)$ or trichlorosilane $\left(\mathrm{SiHCl}_{3}, \mathrm{TCS}\right)$ and hydrogen $\left(\mathrm{H}_{2}\right)$. High purity silicon slim rods are installed in a Siemens reactor, and they are heated by an electric current flowing through them during deposition process. Poly-Si is deposited by thermal decomposition of silanes in a hydrogen environment in a Siemens reactor. Between two types of poly-Si production system, TCS-Siemens reactor is preferred than MS-Siemens reactor because TCS-Siemens is safe and inexpensive process for poly-Si production than MS-Siemens reactor. Therefore, almost $77 \%$ of the poly-Si produced worldwide is currently obtained from TCS-Siemens reactor.

As the price of MS gas decreases, poly-Si production by MS-Siemens reactor was realized as an attractive method for commercialization because low decomposition temperature and high decomposition rate of MS gas have an advantage for lowering the unit cost of Poly-Si production.
The reaction in the Siemens reactor at the specific temperature, the gases undergo the following reactions:

$$
\begin{gathered}
\mathrm{SiH}_{4}(\mathrm{~g}) \longrightarrow \mathrm{Si}(\mathrm{s})+2 \mathrm{H}_{2}(\mathrm{~g}) \\
\mathrm{SiHCl}_{3}(\mathrm{~g})+\mathrm{H}_{2}(\mathrm{~g}) \longrightarrow \mathrm{Si}(\mathrm{s})+3 \mathrm{HCl}(\mathrm{g})
\end{gathered}
$$

The decomposition temperature of MS is $300-500^{\circ} \mathrm{C}$ [1], and, at this temperature, the kinetic energy of the individual silicon atoms is too low to form crystalline structures [2]. MS-Siemens reactors are typically operated at temperatures in the range $800-900^{\circ} \mathrm{C}$ [3]. On the other hand, the decomposition temperature of TCS is about $350-400^{\circ} \mathrm{C}$ [4]. TCS-Siemens reactors are typically operated at higher temperatures than MS-Siemens reactors because amorphous structures might cause chlorine encapsulations [5]. These chlorine encapsulations would cause defects and degrade the quality of the poly-Si. Therefore, typical temperature range for TCS-Siemens reactor is around $1050-1100^{\circ} \mathrm{C}$ much higher than MS-Siemens reactor [6, 7].

Gas flow control is important to increase the productivity of MS and TCS-Siemens reactor because the poly-Si production is produced by CVD method. 


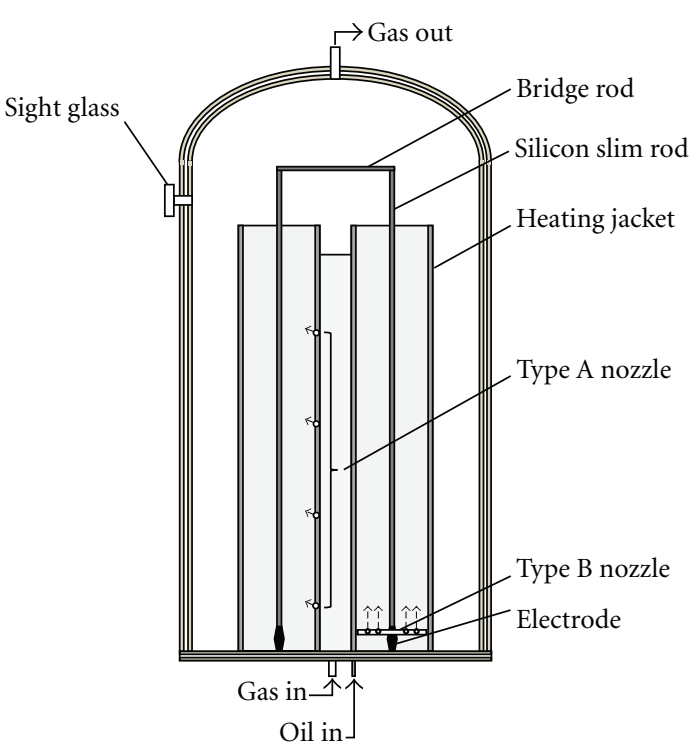

(a)

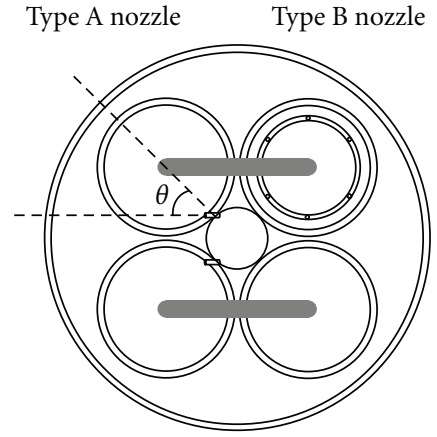

(b)

Figure 1: Schematic diagram of MS-Siemens reactor.

In this study, poly-Si was deposited by MS-Siemens reactor and the gas flow control was tried with two different types of nozzle system. The analysis of mass, heat, flow, momentum, concentration of source gas, and so forth in the inner space of reactor were accomplished by computational fluid dynamics (CFD). It is not easy to confirm the phenomena of heat and flow in the reactor because heat and flow in the inner space of reactor could be changed with the structure, shape, position of nozzle, the flow pattern, and temperature distribution of fluid. The analysis of heat and flow is necessary to understand the deposition behavior of poly-Si in a Siemens reactor. Optimum design of nozzle is suggested for high productivity and economic poly-Si production process through the comparison of simulation and experimental results.

\section{Experimental}

Deposition of poly-Si was performed in a Siemens reactor using $\mathrm{SiH}_{4}+\mathrm{H}_{2}$ system. MS-Siemens reactor is consisted of chamber, nozzle, gas supply system, exhaust system, base plate, electrode, heating jacket, and so forth as shown in Figure 1. 4 highly pure silicon slim rods $(9 \mathrm{~N})$ with thickness of $7 \mathrm{~mm}$ and length of $2100 \mathrm{~mm}$ were used as a substrate. 2 slim rods were connected by a bridge silicon rod. The reactor was equipped with heating jacket around silicon slim rods for preheating of slim rod before applying an electric current and cooling of system temperature during deposition process.

Two different types of nozzle are used in this study called as type $\mathrm{A}$ and $\mathrm{B}$. The type $\mathrm{A}$ is composed of 4 orifices, and they were vertically distributed with constant interval. Each nozzle was set at an angle of 45 degree to the slim rod. The type B was a ring type, consisted of 6 orifices, which sprayed diluted gas from bottom to up at the height of $100 \mathrm{~mm}$.
Experiment was performed with the MS concentration of $4 \%$, deposition time of 55 hours, silicon slim rod surface temperature of $850^{\circ} \mathrm{C}$, and reactor pressure of $3.5 \mathrm{kgf} \cdot \mathrm{cm}^{-2}$.

To understand the behavior of gas flow in the reactor, the commercial CFD software was used. The credibility of CFD analysis has been acquired and recognized through the researches for the transport phenomena of mass, heat, and momentum in the various geometries that have been performed for a long time. The ANSYS FLUENT 12.1 is used as a simulation program to analyze the transport phenomena of fluid and describe the geometry of reactors. According to the geometry of reactor, turbulent and vortex flow could occur and other turbulent and vortex flow could be formed by the momentum, energy, concentration, and so forth. Therefore, it is difficult to calculate the heat and flow of gas mixture directly.

Thus, lots of variables and turbulent models are required to calculate the turbulent effect in the flow of fluid. The realizable k-epsilon turbulent model is applied to precisely analyze the phenomena about wall boundary layer and the turbulent effects for extensive range. To get the reliable results in the simulation, the modeling of reactor and operating conditions were employed with 3-dimensional geometry. 8,500,000 meshes and Intel Xeon CPU $(2.67 \mathrm{GHz} / 2.66 \mathrm{GH})$ with $24 \mathrm{~GB}$ memory were used for calculation.

\section{Results and Discussion}

Experimental conditions and results are shown in Table 1. The type of nozzle was only variable parameter in this study, and the other experimental parameters such as initial rod size, rod temperature, reactor pressure, monosilane flow rate, and concentration were fixed. As deposition time increased, $7 \mathrm{~mm}$ of silicon rod was changed to $45.2 \mathrm{~mm}$ and $62.6 \mathrm{~mm}$ 


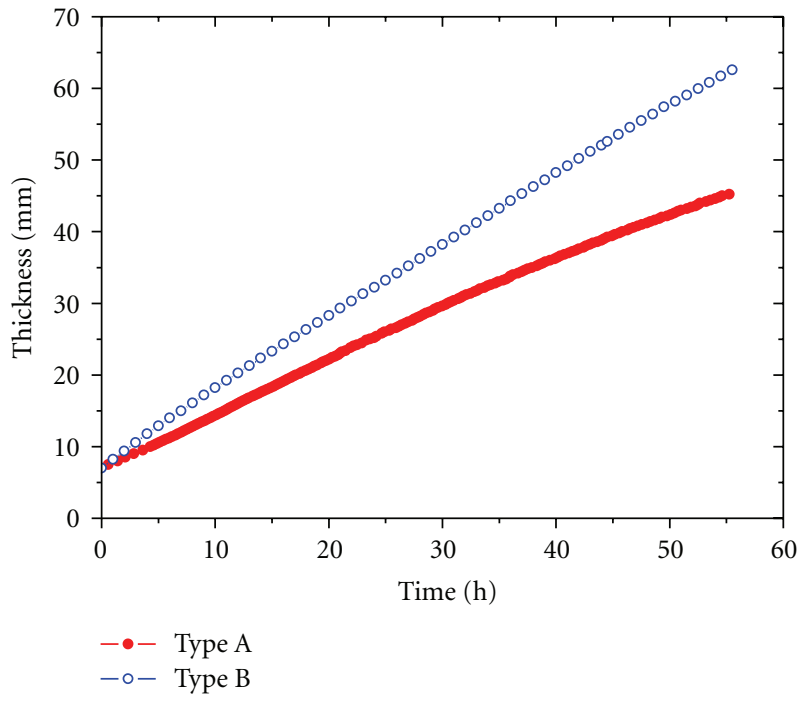

Figure 2: The deposition thickness change of silicon rod with deposition time.

TABLE 1: Experimental conditions and results.

\begin{tabular}{|c|c|c|}
\hline Experimental data & Nozzle type A & Nozzle type B \\
\hline Initial rod size $(\mathrm{mm})$ & $\begin{array}{c}7 \\
(\text { square }) * 2100(\mathrm{H})\end{array}$ & $\begin{array}{c}7 \\
(\text { square }) * 2100(\mathrm{H})\end{array}$ \\
\hline Rod temperature $\left({ }^{\circ} \mathrm{C}\right)$ & 850 & 850 \\
\hline Reactor pressure $\left(\mathrm{kgf} \cdot \mathrm{cm}^{-2}\right)$ & 3.5 & 3.5 \\
\hline $\mathrm{SiH}_{4}$ flow rate $\left(1 \cdot \mathrm{min}^{-1}\right)$ & 5 to 40 & 5 to 40 \\
\hline $\mathrm{SiH}_{4}$ concentration (\%) & 4 & 4 \\
\hline Run time (h) & 55.3 & 55.5 \\
\hline $\begin{array}{l}\text { Silicon deposition thickness } \\
(\mathrm{mm})\end{array}$ & 45.21 & 62.6 \\
\hline Deposited silicon $\left(\mathrm{mm} \cdot \mathrm{h}^{-1}\right)$ & 0.69 & 1 \\
\hline $\begin{array}{l}\text { Energy consumption } \\
\left(\mathrm{kWh} \cdot \mathrm{kg}^{-1}\right)\end{array}$ & 111 & 72 \\
\hline
\end{tabular}

and the amount of deposited poly-Si was $31,320 \mathrm{~g}$ and $60,750 \mathrm{~g}$ for type A and B nozzle, respectively. The changes of silicon rod thickness with increasing deposition time are shown in Figure 2. Deposition rates of poly-Si were calculated to $0.69 \mathrm{~mm} / \mathrm{h}$ for type A nozzle and $1 \mathrm{~mm} / \mathrm{h}$ for type B nozzle. The deposition rate of type B nozzle was larger than that of type A. In order to understand these phenomena, the simulations of each case were performed.

The simulation about the heat and flow phenomena in the reactors and deposition rate on the slim rod were conducted to explain the experimental results.

The simulation results in Figure 3 show that type B nozzle has a larger concentration of MS gas on the $10 \mathrm{~mm}$ position from silicon rod surface than type A. The deposition rate of poly-Si on silicon slim rod surface of type B is also larger than that of type $\mathrm{A}$, and this result matches with experimental result. High deposition rate of type B nozzle is caused by the high MS concentration on the silicon slim rod. MS gas distribution is more clarified in Figure 4. As mentioned above, the type A nozzle is composed with 4 vertically arranged orifices that make the circulation flows around the slim rod. Circulation gas stream of type A uniformly distributes the MS gas in a reactor. Therefore, the deposition rate of type A was relatively lower than that of type B.

On the other hand orifice of type B nozzle was distributed around silicon slim rod. Thus, the stream of gas mixture could be formed around slim rod, and the higher MS concentration of type B increased the deposition rate.

The velocity of gas mixture in an inner wall of heating jacket is shown in Figure 5. In case of type A, strong circulating flow formed inner wall of heating jacket because gas mixture of $\mathrm{SiH}_{4}$ and $\mathrm{H}_{2}$ was emitted from vertically located 4 orifices of nozzle between silicon slim rod and heating jacket. Emitted gas mixture flow upward due to silicon slim rod was being heated. Therefore, gas stream could be vortex flow as shown in Figure 5 .

Gas stream of type B nozzle could be vertically formed around silicon slim rod because gas mixture was emitted to upward from the bottom of silicon slim rod. In this reason, fast deposition of poly-Si was possible.

Figure 6 shows the thickness variation of 4 poly-Si rod according to the height. The thickness of poly-Si varies with deposition position. The highest thickness of poly-Si deposited with type A nozzle was measured at the center of poly-Si rod. It is certain that the vortex gas stream of type A makes nonuniform deposition of poly-Si.

In case of nozzle $\mathrm{B}$, poly-Si was uniformly deposited in whole position because gas stream was formed around silicon slim rod. The average deposition thickness was 62.5 $\mathrm{mm}$, and deposition rate was $1 \mathrm{~mm} / \mathrm{h}$.

Energy consumption is very important parameter for poly-Si production because the power consumption has a larger fraction about $25 \%$ for poly-Si production in a mass production system.

The overall value of energy consumption in this study is shown in Figure 7. 3,490 kWh for type A and 4,381 kWh for type B of electrical power were consumed, respectively. It could be converted to quantitative value such as energy consumption per unit weight of poly-Si, and it was $111 \mathrm{kWh} \cdot \mathrm{kg}^{-1}$ and $72 \mathrm{kWh} \cdot \mathrm{kg}^{-1}$ for type $\mathrm{A}$ and $\mathrm{B}$, respectively. It seems that the energy consumption is closely related deposition rate. High deposition rate of type $\mathrm{B}$ has low energy consumption, and low deposition rate of type A has high energy consumption.

\section{Conclusions}

Deposition of poly-Si was conducted in a MS-Siemens CVD reactor using $\mathrm{SiH}_{4}+\mathrm{H}_{2}$ system. To understand the importance of nozzle design, deposition of poly-Si was conducted two different type of nozzle (A and B). Type A was composed of vertically arranged 4 orifices, and type B was composed of circularly distributed 6 orifices.

Through experiment, it was realized that the type B nozzle is better than type A for poly-Si deposition. Type B 


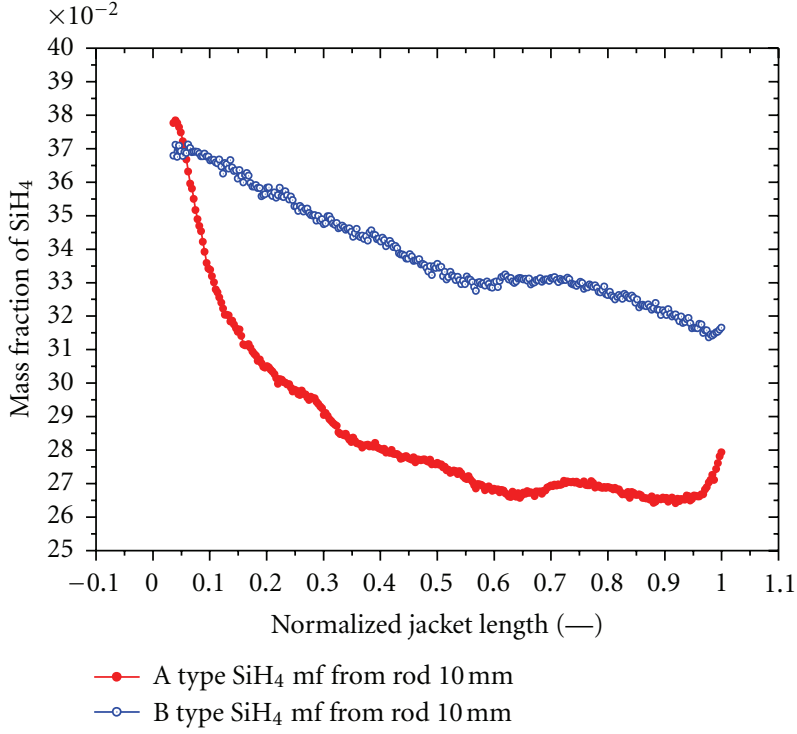

(a)

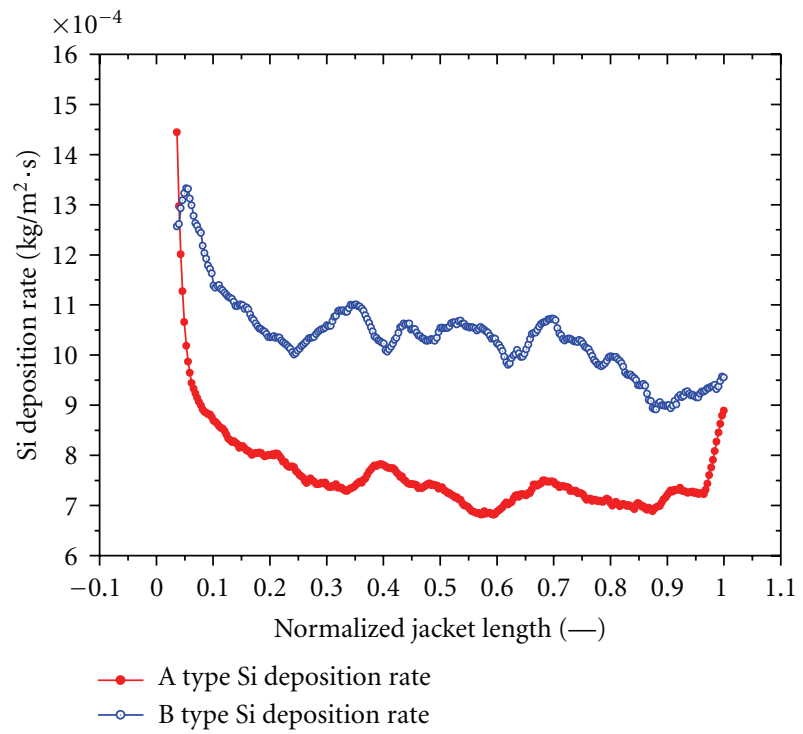

(b)

Figure 3: Simulation analysis of (a) $\mathrm{SiH}_{4}$ mass fraction and (b) silicon deposition rate between type A and B nozzle.

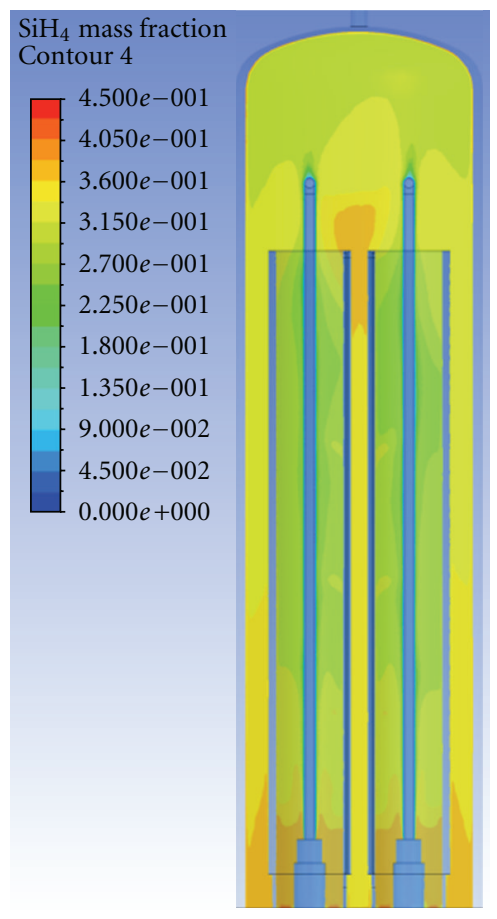

(a)

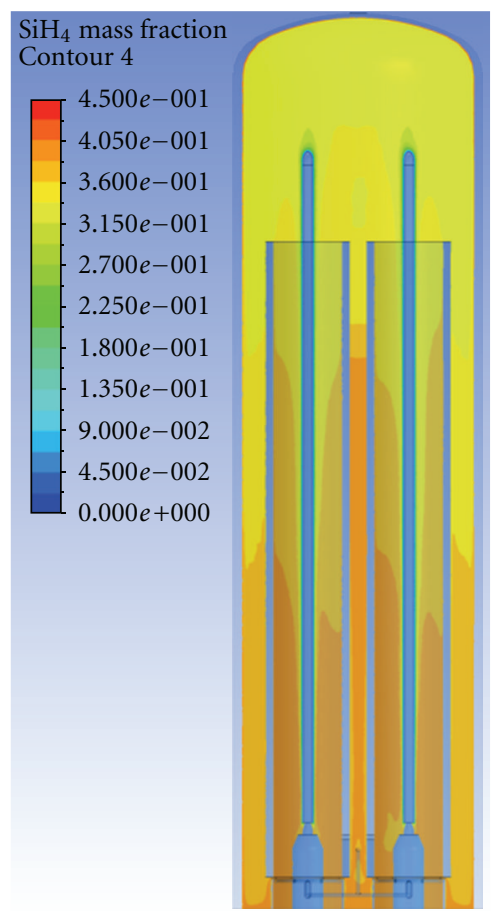

(b)

Figure 4: Simulation analysis of $\mathrm{SiH}_{4}$ mass fraction between nozzle (a) type A and (b) B.

nozzle has high deposition rate, uniform deposition, and low energy consumption.

The highest deposition rate in this study was $1 \mathrm{~mm} / \mathrm{h}$, and lowest energy consumption for production of unit weight of poly-Si was $72 \mathrm{kWh} \cdot \mathrm{kg}^{-1}$.
CFD analysis was performed to understand the experimental results. In the case of type $\mathrm{A}$, the vortex flow was formed in the reactor which makes nonuniform deposition of poly-Si and low $\mathrm{SiH}_{4}$ concentration around silicon slim rod. 


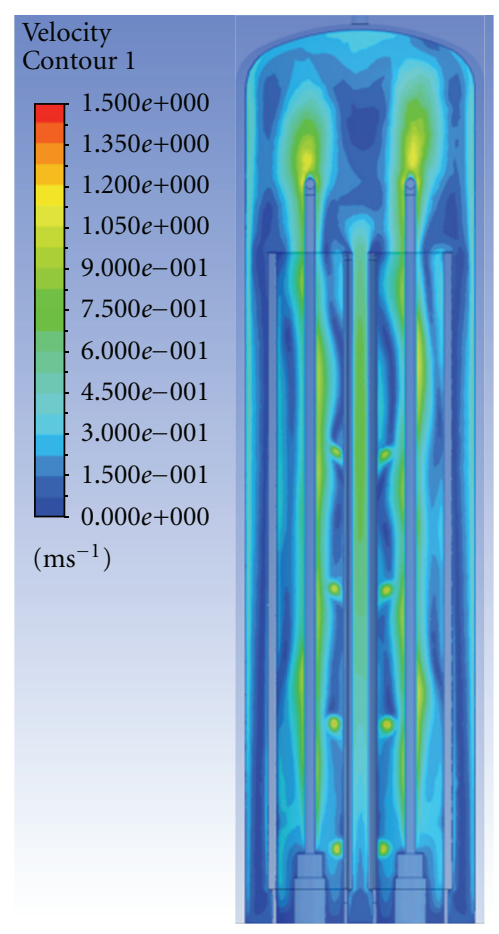

(a)

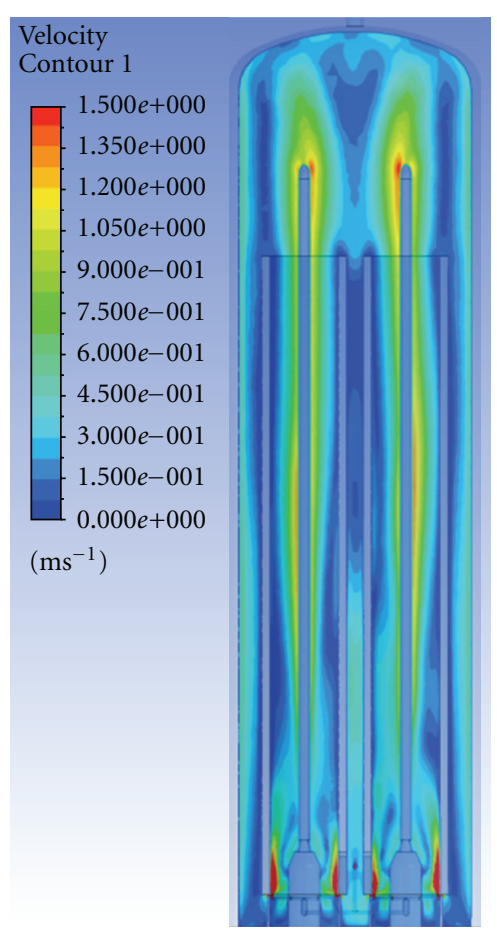

(b)

FIGURE 5: Simulation analysis results of fluid velocity between nozzle (a) type A and (b) B.

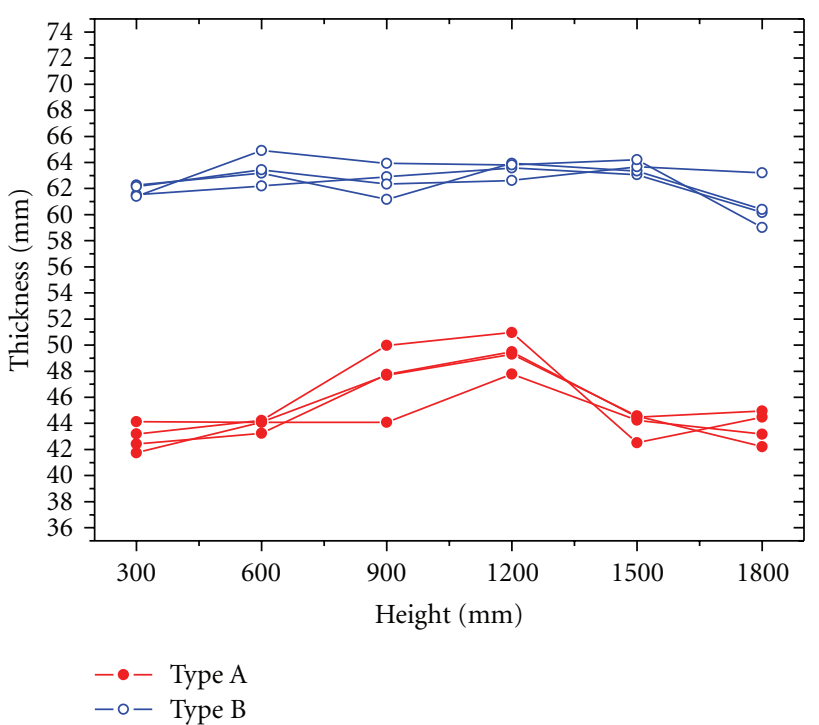

FIGURE 6: Thickness variation of 4 poly-Si rod along the height.

On the other hand, in case of type B nozzle, high concentration of source gas was supplied on the silicon slim rod because gas mixture of $\mathrm{SiH}_{4}+\mathrm{H}_{2}$ flows along the slim rod.

The experimental results with type B nozzle in this study such as $1 \mathrm{~mm} / \mathrm{h}$ of deposition rate and $72 \mathrm{kWh} \cdot \mathrm{kg}^{-1}$ could be adapted as mass production system for lowering the unit production cost.

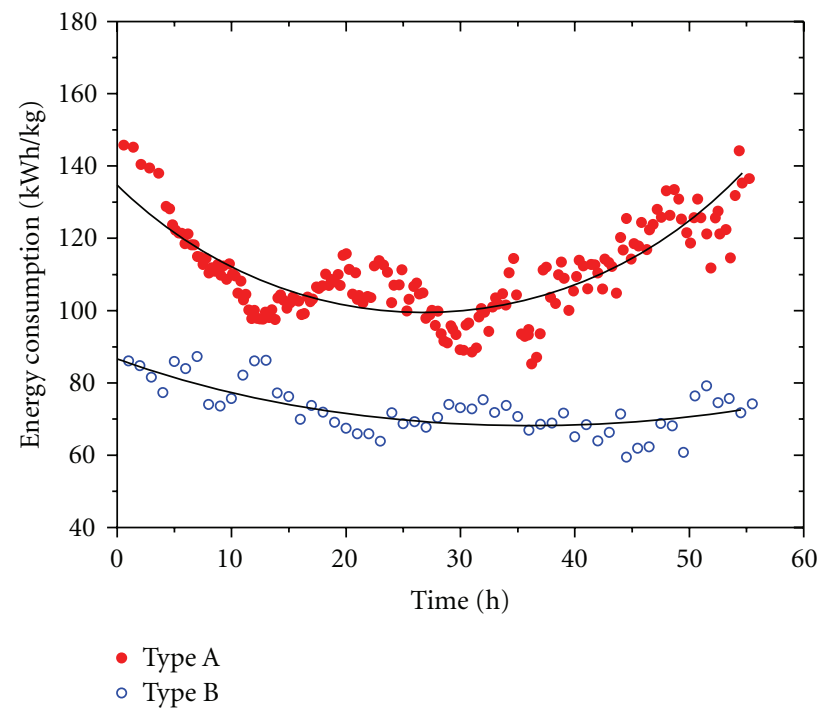

FIgURE 7: Power consumption throughout the deposition process.

\section{Acknowledgments}

This research was financially supported by the Ministry of Knowledge Economy (MKE), Korea Institute for Advancement of Technology (KIAT), and Daegyeong Leading Industry Office through the Leading Industry Development for Economic Region. 


\section{References}

[1] A. K. Praturi, R. Lutwack, and G. Hsu, Chemical Vapor Deposition of Silicon from silane Pyrolysis, JPL Publication, 1977.

[2] W. A. P. Claassen and J. Bloem, "The nucleation of CVD silicon on $\mathrm{SiO}_{2}$ and $\mathrm{Si}_{3} \mathrm{~N}_{4}$ substrates," Journal of the Electrochemical Society, vol. 127, no. 1, pp. 194-202, 1980.

[3] W. C. Breneman, R. N. Flagella, J. M. Gaston, and D. W. Hagan, "Improved process for the production of ultra high purity polycrystalline silicon," patent EP0294908, 1988.

[4] S. M. Load, "Machine for production of granular silicon," patent US 6827786, 2004.

[5] W. O. Filtvedt, M. Javidi, A. Holt et al., "Development of fluidized bed reactors for silicon production," Solar Energy Materials and Solar Cells, vol. 94, no. 12, pp. 1980-1995, 2010.

[6] M. A. Rodgers, "Process for manufacturing pure polycrystalline silicon," patent US 4170667, 1979.

[7] F. Köppl, H. Hamster, R. Griesshammer, and H. Lorenz, "Process for the deposition of pure semiconductor material," patent US 4179530, 1979. 


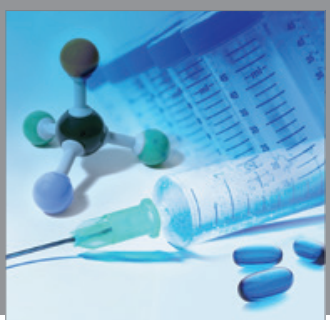

International Journal of

Medicinal Chemistry

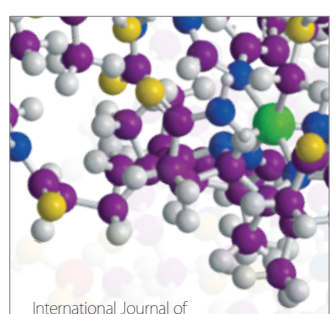

Carbohydrate Chemistry

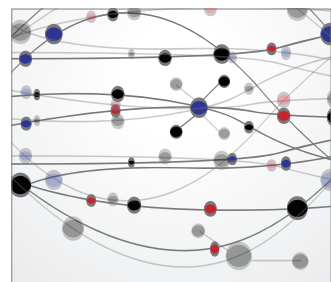

The Scientific World Journal
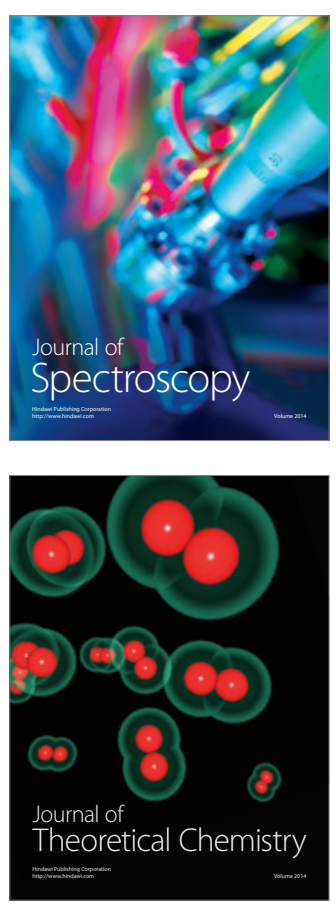
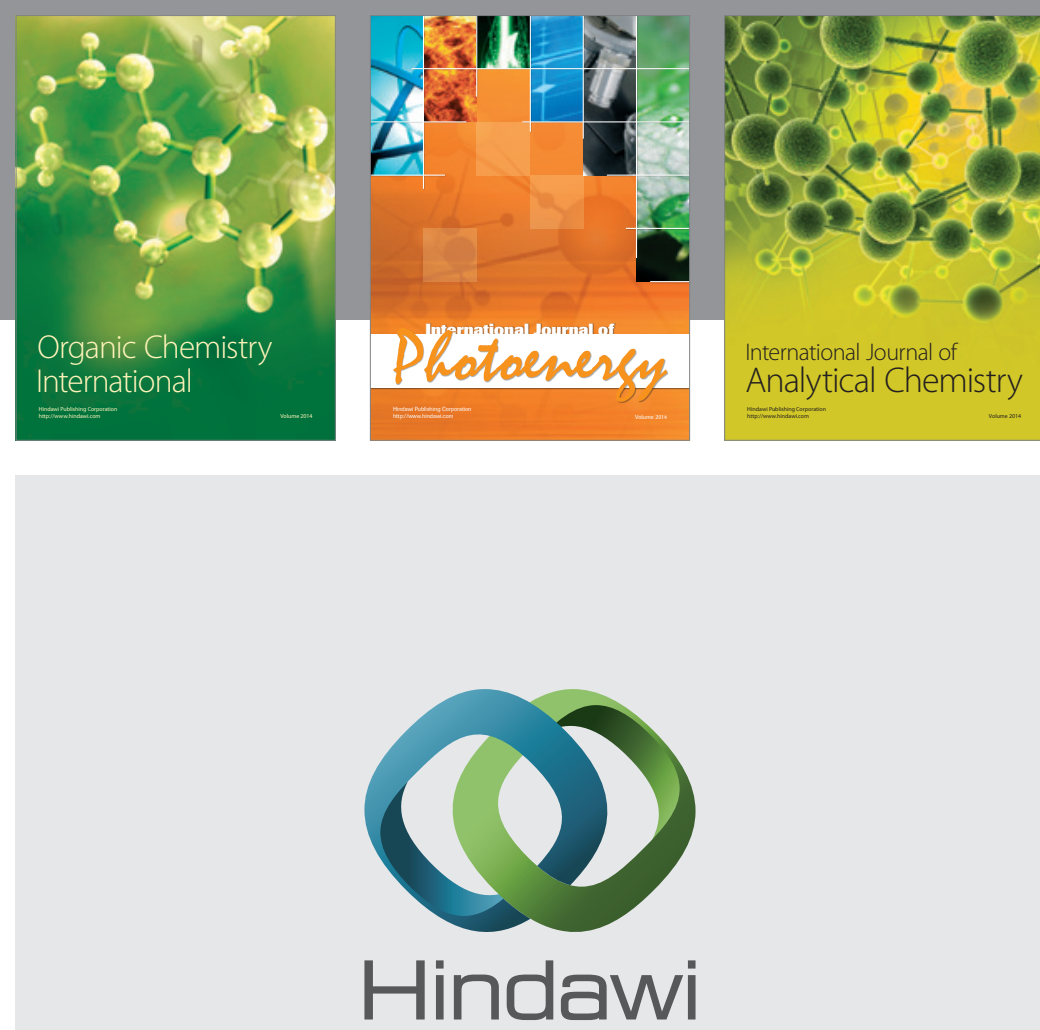

Submit your manuscripts at

http://www.hindawi.com
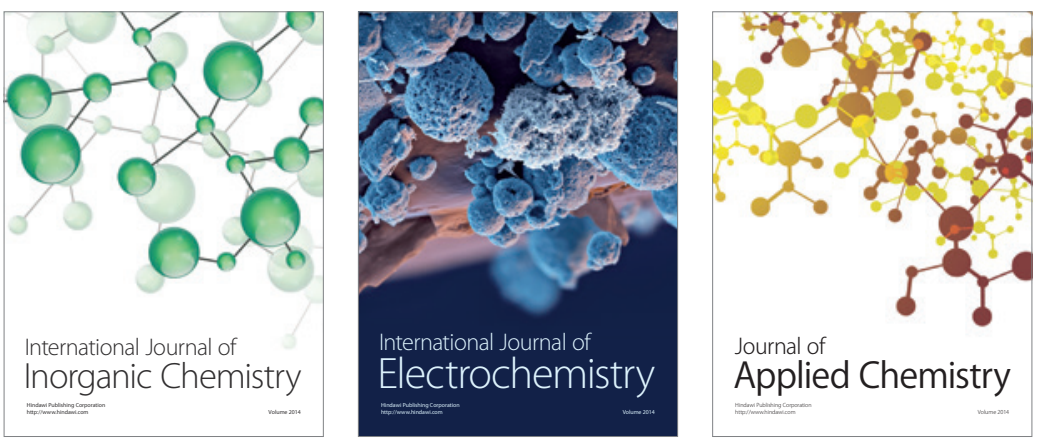

Journal of

Applied Chemistry
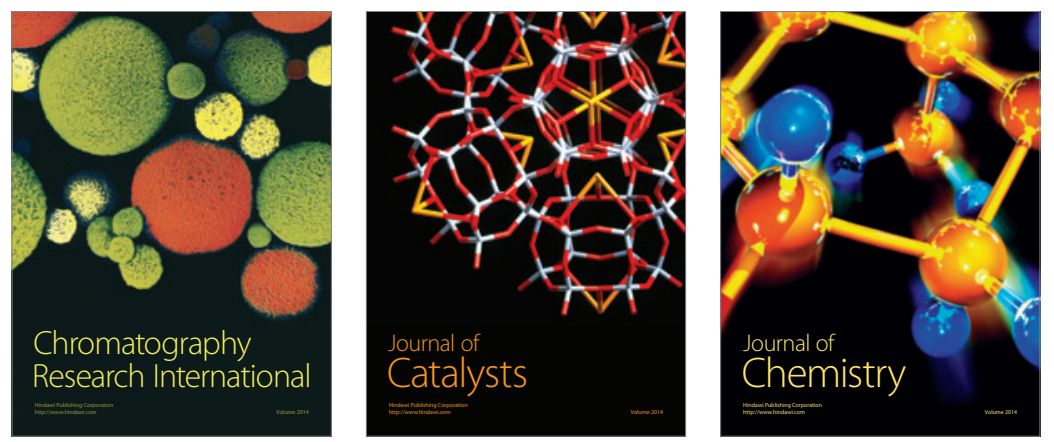
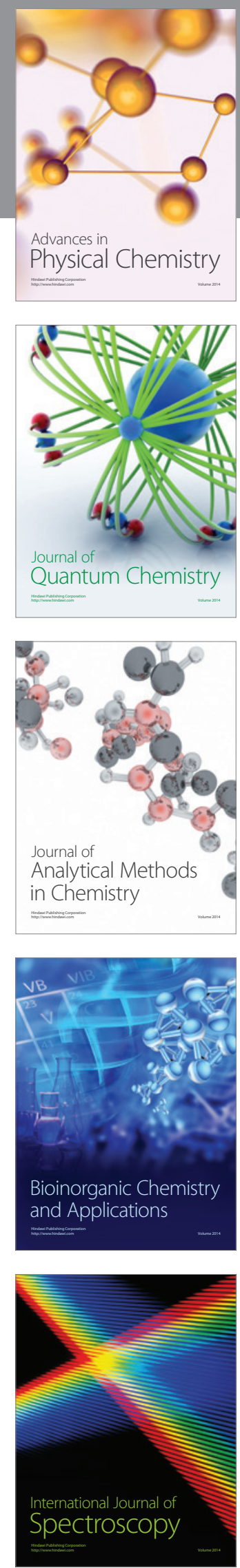